\title{
Indigenous Participation in Australian Sport: The Perils of the 'Panacea' Proposition
}

\author{
John Robert Evans \\ University of Sydney \\ Rachel Wilson \\ University of Sydney \\ Bronwen Dalton \\ University of Technology Sydney \\ Steve Georgakis \\ University of Sydney
}

\begin{abstract}
The argument that participation in sport among disadvantaged populations can produce positive outcomes in wide range of areas has been a consistent theme in academic literature. It is argued that sport participation can promote women's empowerment, sexuality, lifestyle, peacemaking, youth development, poverty reduction and conflict resolution. Similarly, in Australia, participation in sport among Indigenous Australians has been proffered as a 'panacea' for many Indigenous problems; from promoting better health and education outcomes, to encouraging community building, good citizenship and entrepreneurship. Parallel to this has been a focus on documenting and analysing sport participation among Indigenous Australians in elite sport which often concludes that Indigenous Australians have an innate and 'natural ability' in sports. These two assumptions, first, that sport participation can help realise a wide range of positive social outcomes; and second, that Indigenous Australians are natural athletes, have driven significant public investment in numerous sport focused programs. This paper questions these assumptions and outlines some of the challenges inherent with an emphasis on sport as a solution to Indigenous disadvantage. We highlight how participation in sport has often been tied to ambitious, ill-defined and, in terms of evaluation, often elusive social outcome goals. Second, we also argue that there is limited research to indicate that participation in either elite or grassroots level sport has led to any discernible social progress in addressing inequality. We contrast historical Indigenous participation in a range of sporting codes to demonstrate the influence of factors beyond the 'natural ability' and 'born to play' propositions. Finally, we outline six 'perils' associated with viewing sport as a panacea; including how privileging sport can not only perpetuate disadvantage by reinforcing stereotypes and also contribute to a diversion of attention and resources away from other approaches that have been proven to have a greater positive social impact.
\end{abstract}




\section{Introduction and background}

Much of the research on sport and Indigenous Australians has focused on their role in elite Australian sport where Indigenous Australians ${ }^{1}$ have had a significant presence. In some studies, success at this elite level has implicitly been viewed as justification of the benefits of sport participation at the community level. For example, in reference to Indigenous communities, Cashman argues that 'sport was the cement which bound the community together' (1995, p.34). This argument has its roots in earlier historical documentation and has been supplemented by studies which looked at Indigenous sporting issues associated with gender, class, rural/urban divide and various sports using wide and varied methodologies (Fredericks et al. 2002; Tonts 2005; Godwell 2000; Maynard 2010). This literature dates back to work undertaken by Tatz (1987) and Harris (1989) more than a quarter of a century ago, who consistently argued that this focus elevates the place of sport as an institution in Indigenous society.

Tatz's work explores a number of key themes associated with Indigenous sport. He contends that sport has offered Indigenous Australians opportunities to excel and be recognised in a positive form (Tatz 1987; Tatz \& Adair 2009). However popular media has held many sportspeople in awe because of their ability and skill (Bamblett 2013; Godwell 2000; Klugman \& Osmond 2013). Beyond academia it also appears that sport and Indigenous achievement have become inextricably linked in the broader Australian public psyche. For example, these attitudes are typified by the fact that of the Indigenous Australians that have been awarded 'Australian of the Year' four out of a total of eight have been athletes (Lionel Rose, 1968; Yvonne Goolagong, 1971; Cathy Freeman, 1998; and Adam Goodes, 2014). Yet this recognition often creates a dichotomy as it does not recognise the activities or aspirations at a community level. Tatz makes the important claim that sport can make a significant contribution to reducing youth suicide and improving aspects of health and well-being in many communities (Tatz 2012). Tatz also suggests that sport offers many roles for community members other than as athletes. The contested nature or dissonance that represents Indigenous participation in sport is reflected in the work of Kickett-Tucker (2008) and Nelson (2009) who point out that on the one hand there is the highly visible success of elite professional athletes and the endeavours of local communities; while on the other hand

\footnotetext{
${ }^{1}$ The most commonly accepted definition is (ABS, 2012): An Aboriginal or Torres Strait Islander is a person of Aboriginal or Torres Strait Islander descent who identifies as an Aboriginal or Torres Strait Islander and is accepted as such by the community in which he or she lives ... The definition has three elements - descent, selfidentification and community acceptance.
} 
participation in sport for many young Indigenous people may be problematic because of the intrinsic competitive requirements and the need to be highly proficient.

The importance of sport to Indigenous communities and the success of Indigenous elite athletes in the Australian sporting landscape has been well documented (Tatz 1995, Hallinan \& Judd 2009; Norman 2012). But, while the situation in elite level sport is quite positive, this is not the case in other domains (Tatz 2009; Nelson 2009; Adair \& Stronach 2011).

Indigenous Australians account for a small percentage (approximately $2.5 \%$ or 520,000 ) of the total Australian population (ABS 2012); however, they are grossly over-represented as service users of both the health-care and judicial systems. Compared to the non-Indigenous population, Indigenous Australians experience higher mortality and morbidity rates; lower life expectancy; poor education outcomes; low socio-economic status; and poor employment opportunities (see for example Bradley et al. 2007; Norris 2001; Reeve 2012; Vos et al. 2009). For example, in terms of education attainment, a significant disparity exists between Indigenous and Non-Indigenous Australians. This is reflected from primary to tertiary levels. The difference in educational outcomes between the Indigenous and Non-Indigenous population in the 2012 National Assessment Program Literacy and Numeracy (NAPLAN) results is stark. Data comparing Indigenous students in remote Western Australia (WA) to Non-Indigenous Australians shows that whereas 92.6\% of Non-Indigenous Year 5 students met the national reading average, only $32.3 \%$ of students in remote WA met the same standard; this represents a gap of $60.3 \%$. This gap was similarly reflected in writing; whereas 93.9\% of Year 5 Non-Indigenous students met the national average, only 34.2\% of Indigenous students in remote WA achieved this result. The figures do not appear to improve with age (ACARA, 2012).

Indigenous Australians have also been the subject of a wide range of disenfranchising and marginalising government policies; for example, the White Australia policy and policies of assimilation, integration and protection. It was not until 1967 that there was a referendum to have Indigenous people counted in the Census. In 1991 the Royal Commission into Aboriginal Deaths in Custody reported on unacceptable levels of Indigenous incarceration deaths (Beacroft, Lyneham \& Willis 2011). The following year heralded the Mabo Decision, which set aside the notion of 'terra nullius' and introduced the formal recognition of 'native 
title'. Considered together, these events clearly indicate that Indigenous Australians have been the subject of profound social, cultural and economic disadvantage.

The 1991 Aboriginals Deaths in custody enquiry recommended, among other things, that sports programs be developed to further social and anti-crime goals. Since that time increasing levels of government funding have been directed at sports programs aimed at addressing Indigenous disadvantage by attempting 'to close the gap'. The Australian Productivity Commission's 2012 Indigenous Expenditure Report estimates that that total direct Indigenous expenditure at a national level in 2010-11 was \$25.4 billion, accounting for 5.6 per cent of total direct general government expenditure. Of that, Indigenous programs for Recreation and Culture ${ }^{2}$ for 2010-11 accounted for just under half a billion Australian dollars (Productivity Commission 2012).

As a consequence, numerous sport for development initiatives targeting Indigenous Australians have proliferated over the last decade. Some of these programs have been Commonwealth initiatives (e.g. the Indigenous Opportunities Policy, the National Indigenous Health Strategy, National Aboriginal and Torres Strait Islander Education Policy) while others have been initiatives of the States and Territories (e.g. the NSW Aboriginal Education Policy, the NSW Aboriginal Health Plan, the Queensland Indigenous Sexual Health Strategy and the Stronger Futures policy). However, in terms of on the ground programs, many are delivered by not-for-profit (NFP) organisations. In the context of the increasing shift in responsibility to third-sector (NFP) organisations (Lyons 2001; Skinner et al. 2008), increasingly sport for development programs are designed, implemented and run by NFPs, including organisations affiliated with major sporting codes.

This significant public and philanthropic investment in sport-based Indigenous programs is driven by the view that participation in sport has the capacity to deliver a wide range of positive outcomes, from improved education and health outcomes to broader goals associated with social inclusion and community wellbeing, including promoting a sense of belong, leadership and entrepreneurship. In the Australian Productivity Commission's Review of Indigenous Expenditure it states that these sport and recreation based programs were

\footnotetext{
${ }^{2}$ This includes expenditure on other recreation facilities and services such as playgrounds, sporting grounds and recreational parks and gardens, and administration and operation costs associated with recreational and cultural affairs and services such as the Indigenous community sport and recreation officer program.
} 
'vehicles for (re)engaging disengaged youth' (Australian Productivity Commission 2010, p. 225). According to the stated goals of one major Commonwealth Government funded program, The National Indigenous Sport and Active Recreation Program (ISARP), the program:

contributes to Health (by encouraging a healthier lifestyle that includes physical activity), Economic Participation (through employment opportunities for both Indigenous and non-Indigenous people such as sport and recreation officers), Safe Communities (by providing an alternative to anti-social behaviour) and Governance and Leadership (by funding initiatives to build capacity of Indigenous communities to deliver sport and recreation activities independently). (Department of Regional Australia, Local Government, Arts and Sport, 2013).

In many States, ISARP is delivered in partnership with the Police Citizens Youth Welfare Association. According to Queensland's PCYC website, active sport participation objectives in each Indigenous community serviced through the ISARP 'aims to increase Aboriginal and Torres Strait Islander social engagement through active community participation’. In delivering the program the PCYC (2014) is also working towards:

- Building community leaders

- Creating social connections

- Promoting healthy lifestyles

- Supporting volunteerism

- Increasing health and wellbeing

- Preserving cultural values.

Similarly, a report from the Closing The Gap Clearinghouse suggests that there is evidence:

in the form of critical descriptions of programs and systematic reviews, on the benefits to Aboriginal and Torres Strait Islander communities from participation in sport and recreational programs. These include some improvements in school retention, attitudes towards learning, social and cognitive skills, physical and mental health and wellbeing; increased social inclusion and cohesion; increased validation of and connection to culture; and crime reduction. (Ware \& Meredith 2013, p.1)

However, evidence from methodologically strong studies is hard to find and we argue that these claims are overstated. In fact although Ware and Meredith refer to 'systematic reviews', their paper draws primarily upon literature reviews and there are no comprehensive reviews 
of research in this area that discriminate between studies in terms of methodological quality using systematic review methodology, nor any that conduct statistical meta-analyses.

The small number of research evaluations carried out to date have not employed methodologies suited to determining causal relations between sport and outcomes; indeed few of the social outcomes are defined, and fewer still evaluated, within the literature. Research carried out by Cunningham \& Beneforti indicated that this was a difficult and problematic area leading them to make the following comments in their discussion:

It is evident from the literature review that indicator development relating to outcomes from sport and recreation programs (for the general population and even more so for Indigenous populations) is in its infancy. Research evidence on the links between sport and recreation programs and various health and social outcomes is also limited (2005, p.96).

One of the recommendations in response to the Parliamentary Inquiry into the contribution of sport to Indigenous wellbeing outlined in the 2013 report Sport - More Than Just a Game was the need to establish an evaluation framework to assess the impact of sports programs in Indigenous communities (see Commonwealth of Australia 2013, page xiii). This clearly signals that previous efforts to evaluate and monitor outcomes have not been effective. Furthermore once evaluation evidence is available this would need to be appraised in terms of quality and synthesised in systematic reviews and/or meta-analyses.

Overstated claims are also found in the broader international sport for development literature. Coalter (2010) suggests that although there is a theoretical logic to some of these sorts of claims, there are also some inherent dangers. These include:

1. confusing potential micro-level individual outcomes with community and broader macro-level impacts;

2. ignoring wider socio-political contexts within which sport-for- development organisations have to operate;

3. seeking to solve broad gauge problems via limited focus interventions; 
4. encouraging mission drift by sport-for-development organisations wholly dependent on aid from a variety of aid agencies, with often overly ambitious non-sporting agendas. (Coulter, 2010, p.295)

Within this context we examine the challenges inherent in the trend to present sport as an area of natural strength for Indigenous Australians and as a panacea to the challenges they face. We argue that driving much of this faith in the power of sport is a deeply held view that Indigenous Australians are born with innate sporting talents.

\section{'Born to play': An Overview of Indigenous Sport Participation across major sporting codes}

Any attempt to comment on contemporary Indigenous sport issues is problematic without conceptualising the history of Indigenous sport in Australia. In this section we argue that Indigenous participation in sport is heavily influenced by social determinants rather than the racial determinants exemplified in the ‘born to play’ or ‘natural ability’ premises. We argue against the view that Indigenous athletes have a pre-disposition to certain sports is based on racial issues. This viewpoint seems to held by a cross-section of society including spectators, coaches, media commentators and academics who collectively propose that the success of Indigenous athletes is due to their 'natural ability', 'flare' and 'heritage' and who very rarely attribute Indigenous success to hard work and perseverance. Typical of this were comments made by eminent Australian Rules Footballer, Tony Lockett who gave an address honouring Indigenous teammate Michael O’Loughlin and noted:

Mick had something that was a little different. He had real good skills and he just knew where the ball was going to be. He had something special that players can't learn. I think you've either got it or you don't. Those blokes are pretty rare but it's more common among our Indigenous fellas. They just seem to have the knack, that something different.

Hallinan \& Judd note that, as evident in Lockett's comment, Indigenous Australians ability to achieve in sport is often seen as:

due to a set of "unique" prescribed characteristics and traits determined biologically in their "Aboriginal genes and culturally in their "Aboriginal" knowledge 
the abilities and talents of Aboriginal players are not seen as an outcome of perseverance and dedication.... but in terms of racial and cultural determinates (2009, p.2369).

We argue that socio-cultural factors are highly influential and in order to support this standpoint we will use pertinent examples related to the sports of Rugby League, Australian Rules football, Cricket and Rugby Union. These are all prominent Australian sporting codes which provide contrasting historical and current levels of Indigenous participation. We contrast the stories of growth in Indigenous participation in Australian Rules and Rugby league football, with those of Rugby Union and Cricket where Indigenous engagement is much lower.

\section{Australian Rules football and Rugby League}

The football codes (Rugby League and Australian Rules football) are sports where Indigenous athletes have clearly had a significant presence. In various Indigenous communities around Australia, especially in West Australia and the Northern Territory, Australian Football League (AFL) is the premier sport for males, while in Queensland and NSW Rugby League is popular.

The Sydney Morning Herald notes that there were Indigenous athletes playing Australian football in 1860 in a team referred to as the 'Gippsland Blacks' (12 June 1860, p.13). While this demonstrates that Indigenous athletes were playing AFL just two years after the sport was codified in Australia, their presence in the sport from 1860 up until the early 1980s was minimal. Gardiner (1997) estimated from the establishment of the Victorian Football League (VFL) in 1890 until 1980, there were fewer than 25 Indigenous players. This all changed exactly 20 years ago after the Nikky Winmar racism incident (Klugman \& Osmond 2009) where Winmar responded to racial vilification by raising his jumper and pointing to the colour of his body. This 'proud and defiant act' (Gardiner 1997, p.10) sparked widespread awareness about the role of Indigenous players in the game and resulted in the AFL reaching out to Indigenous athletes and communities to be a part of the sport. This policy resulted in an unprecedented growth of elite level AFL players. While up until 1980 there were fewer than 25 Indigenous players in the VFL, in 2012 there were 79 registered players or 11\% of the total number of registered AFL players (AFL Players Association 2013). This historic rise of 
Indigenous representation in AFL is related to the sports openness to inclusion rather than biological race issues.

The AFL's recent support of Indigenous participation is perhaps best reinforced by an incident in 2008 when the AFL celebrated its $150^{\text {th }}$ anniversary. Hibbins (2008) produced a history of the code which noted that AFL had no links to Indigenous ball games, such as 'Marn-Grook'; that is that AFL had no Indigenous influence. This analysis by Hibbins (2008) generated heated debates because it occurred at a time when the AFL embarked on a process of becoming a national sport and the AFL was attempting to link itself to Australia's Indigenous history and thus reinforce its aspirations to be the national sport. As such, AFL had for some time positioned itself as a sport which evolved from the original inhabitants of the land, not from the British such as other football codes Rugby League and Rugby Union. Hallinan and Judd suggest the use of Indigenous players to promote the sport arose from a desire to present the 'relationship between Aboriginal Australia and the Australian game of football as one of amiable historic continuity’ (2009, p.2363). In 1990 the VFL became the National Football League and, by 2013, the link between the sport and Indigenous culture was clear and evident with the Indigenous Round, Dreamtime at the ' $G$ ' as well as the playing roster; which included more than 80 Indigenous players, more than $10 \%$ of the total number of players.

While it has been suggested that Indigenous participation in AFL is attributable to 'a sixth sense' or 'natural athletic ability’ (Hallinan, Bruce, \& Burke, 2005), we argue that these participation rates reflect aggressive recruitment and talent identification programs conducted by the AFL. The AFL conducts a number of Indigenous specific initiatives. The QANTAS AFL Kickstart program for example funds specific development programs for Aboriginal communities in the NT, Northern Queensland and North Western Australia; the 'Flying Boomerangs' program is another leadership program which culminates in a Certificate 2 qualification in Indigenous Leadership; while there is also a National Youth Girls Championship. In addition, the AFL conducts visits to Aboriginal communities, establishes and supports junior football competitions, conducts coaching and umpiring clinics and provides educational scholarships to colleges in the NT. There is no doubt that the AFL has a strong link to the Indigenous community and in most Indigenous communities outside of NSW and Queensland, Australian Rules football is the sport of choice. The AFL has permitted the entry of Indigenous athletes into the sport, not only for the sake of improving 
Indigenous and Non-Indigenous relations, but because of their perceived 'natural athletic ability’ (Hallinan, Bruce \& Burke 2005).

Rugby League has also been another football code where there has been a distinct Indigenous presence. In the 2011 Rugby League National Census, Indigenous Australians made up 3.39\% of committee members at registered clubs, 5.8\% of all registered Rugby League players, $8 \%$ of National Toyota Cup players, 12\% of NRL players, 21\% of State of Origin players and 35\% of the Australian National team. Moreover, 8,830 males and 532 females were listed as playing organised Rugby League in 2012 (ARLC 2012).

The history of the Indigenous presence in Rugby League is often misunderstood even though there are a number of accounts (Hartley 2002; O’Neill 2005). The documentation of Indigenous Rugby League players has for the most part reinforced the notion that Indigenous athletes were discriminated against, although this fails to locate this discrimination in a wider sporting context. Typical of this was the work undertaken by Hartley who argued that the Redfern All Blacks Rugby League Football Club ‘provided the Indigenous community of Redfern with a vehicle of resistance to depressed socio-economic conditions, to racial discourses and to discrimination' (2002, p.149). Established in 1944 and playing in the South Sydney District Junior Rugby Football League, the club flourished in a time when the official policy of assimilation was at its peak. The Club was one of the many which existed in the South Sydney district and included Redfern United and La Perouse United. The Club played in the mainstream South Sydney Junior Competition in a game which was Anglo-Celtic in origin. There is no doubt that the Redfern All-Blacks had confronted racism and there is no doubt that Hartley's (2002) analysis is correct that Rugby League was not a crucible of tolerance. What Hartley and other contemporary scholars overlook is that even though this racism occurred in Rugby League itself, the code had allowed Indigenous teams and players into competition; a situation which did not occur in other sporting codes or in other political and economic domains. So advanced were relations in Rugby League (compared to other domains) that by 1973, an Indigenous Player, Arthur Beetson, captained the national team (Cottle \& Keys 2010).

This link between Indigenous culture and Rugby League continues to the present day. Not only is there a significant presence of Indigenous Rugby League players in the NRL, there are a number of Indigenous Rugby League teams and competitions. Indigenous teams all come 
together in the annual 'Indigenous Rugby League Knockout Carnival' (Norman 2012). This knockout carnival is the largest gathering of Aboriginal people in Australia, and has a deep significance to the Indigenous community (Norman 2009, 2012). It has been posited that this event is a contemporary cultural practice providing opportunities for congregation and competition. In 2010 a landmark in Indigenous Rugby League occurred when the Indigenous All-Stars game was inaugurated. At this annual clash, an Australian Indigenous team (The Indigenous All Stars) plays a Non Indigenous team (The Australian All Stars) (ARLC, 2012).

\section{Rugby Union and Cricket}

While the section above demonstrated that the presence of Indigenous athletes is clearly linked to those sports that have allowed their inclusion, there are a number of sports which have not been as inclusive and have a limited Indigenous presence. These sports show that the link between participation and lack of participation is based on the philosophy of the sport rather than racial or other issues.

The sports of Rugby League and Rugby Union share many aspects in common. In 2013, former Rugby League international Israel Folau was able to make a strong transition to Rugby Union, starring for the Wallabies in the Tests against the Irish and British Lions. In fact for more than a century there has been a steady stream of Rugby Union players transferring their allegiances to Rugby League (Howitt 2008). While these two football codes are very similar, the presence of Indigenous athletes in Rugby Union is minimal (Tatz 2012). The lack of Indigenous presence has been linked to issues related to class, that is Rugby Union is an exclusive sport played in the private school system, although this thesis is not supported as it does not explain the strong presence of Polynesians in Rugby Union (Zakus \& Horton 2009). We argue this is more related to Indigenous athletes being excluded from the game of Rugby Union.

The elitism of Rugby Union is manifest in a number of different ways. Writing the history of the Mosman Rugby Union Football Club, Hewitt set the tone of his book by noting 'Mosman had come far in just 60 years when only a few docile Aborigines inhabited its bushy foreshores’ (Hewitt 1996, p.1). In fact there is no substantive Indigenous presence until the appearance of the first national player, Lloyd McDermott, who played for the Wallabies in 1962. McDermott, who received a scholarship to attend The Anglican Church Grammar School, was introduced to Rugby Union at this school (Tatz 1995). McDermott would be the 
last national representative until the appearance of the Matraville High School educated Ella brothers who in 1977 represented the Australian Schoolboys. Apart from the sporadic appearances of the players mentioned above, there has been very little attempt by the Rugby Union fraternity to link up with the Indigenous communities. There is one exception to this and this is the work that has been undertaken by the Lloyd McDermott Foundation, which has expressed a commitment to increasing participation rates for Aboriginal men and women in Rugby Union. The foundation organises rugby competitions for Aboriginal Youth, and provides coaching and skill development clinics (Australian Rugby Union 2013). In comparison to the work undertaken by Rugby League and AFL this is a small venture. It is also clear that Rugby Union have not reached out to Indigenous communities with the same success.

The sport of cricket provides another relevant example in the contemporary Australian landscape; it is a sport which has currently no significant Indigenous presence. This was not the case in the 1800s when Indigenous participation in the sport was comprehensive. It is not well-known that the first Australian cricket team to tour Britain was the Indigenous team which toured England in 1868 (Farquharson \& Marjoribanks 2006; Gemmell 2007; Mallett 2002; Maynard 2009). The team played 47 matches throughout England, winning 14, losing 14 and drawing 19 (Mallett 2002; Whimpress 1999). The first non-Indigenous team to tour occurred more than a decade later in 1878.

The playing of cricket by Indigenous people took place very early in Australian colonial history because the British believed that the playing of this sport would 'civilise' Indigenous youth and hence it was popular in missions. The best example of this is the cricket which took place at Poonindie by Reverend Hale in the 1850s, where Indigenous teams played against non-Indigenous teams. Consequently the history of Australian cricket is full of Indigenous athletes playing in the mid to late 1800s. Players such as Johnny Mullagh, Twopenny, King Cole and Johnny Cuzens are among the Indigenous names that feature prominently (Mallett 2002). However this all changed in 1901, when Indigenous Australians were excluded from mainstream activities by the White Australia Policy and overnight Indigenous Australians stopped playing cricket. Since that period there has only being one Indigenous player, Jason Gillespie, to represent Australia in Test cricket. 
In spite of the well documented Indigenous cricket history, the dominant arguments for the low participation levels of Indigenous people in the sport have typically centred on the accessibility of cricket to the Indigenous community. Richardson exemplifies this idea in his suggestion that 'sports like cricket and swimming are not as accessible as they require more equipment or specialized facilities' (2012, para. 10). Until recently Australian cricket has predominantly comprised players from an Anglo-Celtic background and cricket authorities have had limited engagement with Indigenous athletes and communities.

History demonstrates that Indigenous Australians have experienced success in sports that they have been encouraged to participate in. The high participation rates of Indigenous players in AFL and Rugby League, and the underrepresentation of Indigenous players in cricket and Rugby Union, are evidence of this.

This is consistent with international research which dispels many of the racial and biological 'natural strength' and 'born to play' assumptions (see for example: Pitsiladis, Bale \& Sharp 2006; Stone, Perry \& Darley 1997). Regrettably these research findings have not been widely disseminated or acknowledged within Australian sporting communities. Despite important academic insights into the racial and social dynamics of sport (Adair \& Stronach 2011; Godwell 2000), research has made little impact in discussions related to Indigenous sport in Australia. Many continue to justify programs on the basis of the' natural strength' and 'born to play’ propositions. For example, Robert De Castella justifies his 'Indigenous Marathon Project' on the claim that Indigenous Australians have higher proportions of slow-twitch muscle fibers; while McCallister (as cited in Adair, 2012) justifies his program on the basis of Indigenous people having a higher proportion of fast-twitch fibers. Both views have been discredited by recent research related to race and sport.

\section{The perils of 'Sport is the Panacea' Proposition}

The ‘natural strength' and 'born to play’ premises and a range of other factors have conspired to produce policy which reflects faith in the power of sport as a panacea to all dimensions of Indigenous disadvantage. Increasing budgets, overstated claims and a distinct lack of evidence now characterise the scene. We know that sport is a valued institution in Indigenous society; we also know, undisputedly, that sport and physical activity is helpful in promoting physical health - and to a lesser degree mental health. There are also theoretical foundations 
for linking sport to broader social outcomes. These provide strong foundations for the development of sport programs and the potential for them to deliver positive outcomes. However, in the absence of a strong body of evidence to support these programs, particularly in relation to social outcomes, we need to ask whether there are also risks associated with the promotion of sport as a panacea. We now outline six perils, or risks, associated with the panacea position: the reinforcement of stereotypes; disparities in relation to Indigenous youth health; promotion of only a particular type of athlete - seen but not heard; the positioning of sport as the only way to the top; the intrusion of Corporate Social Responsibility (CSR) and NFP agendas; and the diverting of attention from the day to day realities of Indigenous Australians.

\section{Reinforcing of stereotypes}

Indigenous athletes have been highly successful in a narrow field of sports, such as Rugby League and Australian Rules football, as noted above. There are a number of reasons for this discussed in the literature and these are summarised as the following: there is possibility for professional careers in these sports; these sports are easier to access and cheaper compared to rowing, skiing, cycling and tennis where you need specific facilities (courts, snow) and equipment (racquets, bike); these sports are traditionally classless, unlike rugby union, cricket and tennis; these sports have an increasing number of Indigenous role models; and these sports have a mass following and are mainstream sports (Tatz, 1995; Tatz \& Tatz 2000; Maynard 2012; Tatz \& Adair 2009; Tonts 2005; Atherley 2006). This paper has argued that Indigenous athletes succeeded in the sports where they were encouraged to participate. This is perhaps best typified by the example of AFL, where the current player roster has more than 10 per cent representation of Indigenous players despite the fact that earlier in the VFL there were fewer than 30 players in almost a century of competition.

There is considerable research (Hallinan \& Judd 2009; Cottle \& Keys 2010; Adair \& Stronach 2011; Hallinan et al. 1999; Hallinan \& Judd 2012) to suggest that the success of Indigenous Australians in male contact sports such as Australian Rules football and Rugby League simply reinforces stereotypes. That is, their success in these sports is based on their predisposition to excel because they are genetically superior to other races. Athletes such as Anthony Mundine, Cathy Freeman and Michael Long have had success in the sporting arena, and whilst their prominence has lifted the profile of Indigenous sportsmen and women, the inclusion and participation of Indigenous athletes in professional sport has provided 
'evidence of the persistence of racialised thinking' (Hallinan \& Judd 2009, p.1229). Oftentimes prominent Indigenous athletes are portrayed, by the media and sporting organisations alike, as symbols of what is perceived by white Australia to be the continued progression of race relations in this country; whilst simultaneously being undermined by a common belief in genetic predisposition towards kicking 'the freak goal' or doing 'the magical stuff' (Tatz 2012; Hallinan \& Judd 2009, p.1228). Such belief is routinely reinforced by the everyday thought of many managers, coaches and especially journalists (Hallinan \& Judd 2009). Success in sport could be a type of hegemony contributing to the malaise. Further to this, we can assess how the practices of certain sporting leagues have acted to simply confirm colonial marginalisation and stereotypes through the positioning and responsibility given to those Indigenous people who play or are otherwise involved in the sport (Tatz 2012). In many cases, there is a significant and noticeable lack of Indigenous officials placed within coaching and administration staff, whilst the Indigenous athletes often characterised by speed and agility - were found to be commonly assigned positions that relied on athletic ability and not leadership and intellectual skills, which further solidifies stereotypes of Indigenous inadequacies (Hallinan \& Judd 2009).

The over-representation of Indigenous athletes reinforces the idea that Aboriginal people are 'only good at sport' and that it is 'not an Aboriginal thing to be smart' (Sarra 2005, p. 11). More focus needs to be placed on a wider range of role models to dissolve the illusion that Indigenous Australians ‘are either good athletes or good artists’ (Sarra 2005, p.6). Although these successful athletes provide a positive representation of Indigenous Australians, a wider range of Indigenous role models need to be acknowledged. Stereotypes of success in sport also reinforce the view that they are a homogenous group. Furthermore, all Indigenous people are expected to possess the physical capabilities and talents of these athletes and thus there is pressure to meet society’s ideals and expectations which are reflected in these stereotypes.

\section{Disparities with Indigenous Youth Health issues}

While indigenous youth are over-represented in some sports, their health outcomes are poor. Indigenous youth (aged between 15 and 24 years) were more likely to be overweight or obese than non-Indigenous youth (37\% and 27\% respectively), and twice as likely to be obese (15\% and 6\% respectively). Only one in twenty (5\%) of Indigenous youth living in non-remote areas met both the daily recommended serves of fruit and vegetables; significantly lower than the rate for non-Indigenous youth (ABS 2011-2012 National Aboriginal and Torres Strait 
Islander Health Survey). This is largely attributable to the lower levels of fruit consumption among Indigenous young people, where fewer than 20\% met the guidelines for fruit consumption compared and only 15\% who meet the guidelines for vegetable consumption. For Indigenous Australians, 'being overweight or obese, being physically inactive and consuming a diet low in fruit and vegetables have been estimated to contribute to the high rates of cardiovascular disease, diabetes and chronic kidney disease experienced by Australia’s Indigenous people' (Australian Institute of Health and Wellbeing, 2012, p.1). Further, Indigenous youths were 10 times as likely to have a sexually transmissible infection, six times more likely to become teenage parents, and three times as likely to be daily smokers.

Herein lies the paradox of the sporting panacea; given the proven links between sport, physical activity and improved health outcomes (Janssen \& LeBlanc 2010; Janz et al. 2010; Blair \& Morris 2009), it would be anticipated that Indigenous sporting participation would lead to improved health outcomes. While there is some evidence that Indigenous sports participation is associated with higher general and mental health rates (Dalton, Wilson, Evans \& Cochrane 2014) and it is undoubted that sport and physical activity is instrumental in wellbeing, it is also clear that there has been little change in the health status of Indigenous Australians (Australian Institute of Health and Wellbeing 2012) despite grassroots programs, like NASCA, being active in Indigenous communities for more than ten years. We are yet to see comprehensive evidence of their effectiveness (Australian Council for Educational Research 2011, Commonwealth of Australia 2013).

Coulter, commenting on the sport for development movement, points out the dangers of 'confusing potential micro-level individual outcomes with community and broader macrodevelopment impacts' (2010, p.295). Thus one issue to address is the clarity with which programs, evaluations and claims distinguish between individual and community-based outcomes. There is a risk that the panacea approach promotes the 'micro', individual success stories, while neglecting the 'macro' statistics regarding Indigenous society.

\section{Promotion of only a particular type of athlete}

In the opportunities Indigenous people have had to participate in mainstream sport, they have been required to ‘tread a delicate path’ (Malcolm 2007, p.1). To be accepted into mainstream Australian society, Indigenous athletes have been forced to simultaneously deny and celebrate their Aboriginality (Malcolm 2007; Tatz 1995). That is, Australians seem to 
embrace Indigenous participation as an indication of improving race relations in Australia. However, when these athletes express political sentiments or 'have a voice' they are criticised and labeled ‘Un-Australian’. In 1994, Cathy Freeman was heavily criticised for performing a lap of honour at the Commonwealth Games with the Aboriginal flag draped around her shoulders. Critics chastised her for politicising her sport, and deemed her behavior 'unAustralian’. Anthony Mundine has faced a similar predicament. While revered when winning boxing bouts, Mundine has faced significant criticism for speaking out about Indigenous issues. Notably, in October 2012, Mundine appealed for a change of national anthem, as he believed 'it was the theme song for the White Australia Policy'. Finally Nicky Winmar's protest to racist taunts in 1993 elicited this response from the then president of the Collingwood football club: Aboriginal people would be respected 'as long as they conducted themselves like white people', confirming the notion that Aboriginal athletes should be seen and not heard.These incidents highlight the tenuous relationship between Indigenous Australians and elite sport - athletes are widely accepted and even celebrated when they are passive and apolitical, however they are condemned when they seek to highlight the historical inequities that have plagued the Aboriginal condition.

\section{Sport: The only way to the top}

It is rare for media to expose or promote Indigenous people who have succeeded outside of the 'sport' arena, such as displaying academic success among Indigenous cultures, for example Kath Walker, poet, or Neville Bonner, politician. This strengthens the notion that Indigenous people are only successful in one area of society, 'sport', as we do not see or hear about other great things Indigenous people may be successful in. This pigeon-holes Indigenous cultures and therefore limits their opportunities/success among other potential professions, as there are limited role models of Indigenous lawyers, nurses, doctors or teachers to break the stereotypical characteristics of Indigenous people. As Godwell questions, 'the success of many Aboriginal... athletes stand as a testament to individual skill and fortune. But can these efforts also be cited as evidence of Indigenous peoples making gains in all aspects of their lives?' (2000, p.13).

Godwell (2000) maintains that Indigenous people subsequently 'run the risk of being typecast in life as sportspeople' (2000, p.16). Thus, this emphasis on sport can limit Indigenous children's life aspirations as it can influence them to pursue sporting careers rather than other educational and career opportunities. While a significant number of Indigenous athletes are 
found in professional sport, this only represents a fraction of the total Indigenous population. Not only this, but most of these athletes are male. Therefore there is a significant issue with the messages that arise from presenting sport as the remedy to the ills affecting the Indigenous condition; not only does this disenfranchise Indigenous youths who dislike sport or who do not have the potential to play at an elite level, it also presents sport as the only option for a better future. In marginalising Indigenous Australians into this narrow category of being, achievement in other domains, such as education, the arts or business is neglected. It also means that over time Indigenous youth adjust their aspirations to their perceived chances of success. For Indigenous communities sport is presented as the pathway to success. The experience of Black Americans warns us that there is a danger in pursuing such a focused approach (Hoberman 1997).

Intrusion by Corporate Social Responsibility (CSR) and Not-For-Profit (NFP) agendas As part of a wider process of mainstreaming the delivery of Indigenous social services, including many sport related community development programs, increasingly sport for development programs are delivered by not-for-profit (NFP) organisations, including organisations affiliated with major sporting codes (Altman 2004; McCausland 2005). Kidd also notes the role of NFP organisations auspiced by high profile Olympians seeking to 'give something back’ (2008 p.372). The increase in social responsibility activity by high profile athletes, such as Ian Thorpe and Cathy Freeman through their respective foundations, are cases in point. With this, the allocation of substantial public funding to non-governmental organisations marks a significant paradigm shift; according to Houlihan and White, to the 'service paradigm of sport for development (2002, p.218).

Like initiatives of government, few sport programs are evidence based. This is partly due to lack of sufficient evidence but also ongoing deficiencies in evaluation capacity within NFP organisations. This is more than a resourcing issue. In many cases, investment in evaluation has failed to compete with other NFP organisations' priorities. As noted above there is a distinct lack of evidence that links sport participation among Indigenous peoples to positive health, social and education outcomes. Part of the evidence gap is due to a lack of basic data. The Human Rights and Equality Opportunity Commission report notes the inconclusive nature of existing data arguing that: 
while there is a plethora of information available on the general number and characteristics of Australian people who participate in sport and recreational activities (including age, gender, frequency and type of participation), very little data focuses on the ethnic or cultural background of participants'. (Oliver 2006, p.19)

Little has been invested in rigorous evaluation. As much of the literature suggests, there is a lack of monitoring and adequate evaluation of the effectiveness of the expanding nature of sport for development programming (Coalter 2010; Donnelly, Atkinson, Boyle \& Szto 2011; Levermore 2011). When evaluations are undertaken, often NFPs are conflicted, seeking to prove the efficacy of their programs to ensure ongoing funding.

Then there is the issue of over-claiming the benefits of the programs at the outset. Expectations regarding the impact of participation in sport are often high, vague and very broad. To take just one example, a research project commissioned by the Australian Sports Commission (ASC) and Laureas Sport for Good Foundation and conducted by the University of Queensland academic, found that 'learning to surf builds self-esteem of Indigenous youth and enhances community connections' (Australian Sports Commission 2012). Having such ambitious (and arguably tenuous) outcomes, for example empowerment or good citizenship, is technically challenging if not impossible to measure. As some scholars argue, such broad outcomes are difficult to measure in particular when NFPs conduct their own evaluations (Levermore 2011). Houlihan \& White explain that:

given that so much of sports development activity is directed towards the achievement of complex social outcomes, such as safer communities and social inclusion, it will be difficult to identify indicators which provide valid evidence of specific contribution that sports development is making to social outcomes (2002, p. 214).

As a result many NFPs have uncritically adopted sport as a useful and appropriate instrument for meeting health, education and other broader 'empowerment' goals. With the lack of empirical and scientific claims to effectively evaluate the efforts of NGOs, scholars critique the political and economic environment that substantiates the new focus on entrepreneurship (Coalter 2010; Darnell 2007; Darnell \& Hayhurst 2011; Donnelly, Atkinson, Boyle \& Szto 2011; Kidd 2008; Levermore 2011). 
In the case of NFPs associated with major sporting codes, many seek funding from large corporations. In this way, some major sporting codes have characterised their investment in Indigenous sporting initiatives in terms of Corporate Social Responsibility (CSR). Arguably these account for the largest non-government investment in Indigenous programs in Australia. Investment in community sport programs provides an opportunity to contribute to individuals and communities but also has the added advantages of giving particular sporting codes the opportunity to identify and recruit sporting talent and serve to perpetuate their public image as a provider services to marginalised Indigenous youth. Again, these sorts of interest risk compromising the development of a rigorous evidence base for the effectiveness of programs in terms of community outcomes. The value of private and NFP managed investment in these programs may go unquestioned, or only superficially examined.

\section{Conclusion}

While sport certainly plays an important role in Indigenous communities, we must be wary of presenting sport as a panacea for the issues plaguing Indigenous communities. In this paper we have examined how current perspectives are often built upon 'natural talent' and 'born to play' premises. These premises are not supported by the history of Australian sporting codes, nor by international research. Sports stars can be excellent role models and sporting programs clearly yield significant benefits for Indigenous people; however if we tie sport too closely to Indigenous success, then not only are we disenfranchising Indigenous people who do not excel at sport, we are further marginalising Aboriginal people into a narrow category of being (Hall 1997). We have outlined six ways in which accepting sport as a panacea can have negative consequences. Hallinan et al. (2004) suggest that assuming Aborigines are good at sport perpetuates discourses of racialised understandings of difference, reinforcing engrained racism. We have argued that such depictions may become a self-fulfilling prophecy for Indigenous people who seek to be 'good at sport' as they cannot see other options. Placing sport on a pedestal may minimise the importance of achievement in other domains (Hall 1997). Furthermore, we cannot neglect funding to other program areas in pursuit of the positive, and media friendly, stories of elite Indigenous athletes and grassroots sports programs in Indigenous communities. To date there is a paucity of evidence to support the efficacy of the many sports programs that have proliferated in the last decade. Such programs need to be built on evidence; reliance on the belief that sport is good and particularly good for Indigenous Australians is not enough. The relative effectiveness and cost-benefits of sport 
programs, when compared to educational and social programs, must be considered. Thus, while sport is certainly central to Indigenous communities, it must form part of a broader cultural landscape, which includes and promotes participation and achievement in a wide range of areas.

\section{References}

Adair, D. (2012). Ancestral footprints: assumptions of "natural” athleticism among Indigenous Australians’. Journal of Australian Indigenous Issues, 15(2), 23-35.

Adair, D, \& Stronach, M. 2011, 'Natural born athletes? Australian Aboriginal people and the double-edged lure of professional sport', in Long, J. \& Spracklen, K. (eds.), Sport and Challenges to Racism, Palgrave MacMillan, London.

Altman, J. 2004, Indigenous Social Policy and the New Mainstreaming, Centre for Aboriginal Economic Policy Research, Seminar Notes, Australian National University (ANU), Canberra.

ARLC. (2012). Submission to the House of Representatives Standing Committee on Aboriginal and Torres Strait Islander Affairs Inquiry into the Contribution of Sport to Indigenous Wellbeing and Mentoring. Canberra

Atherley, K. M. (2006). Sport, Localism and Social Capital in Rural Western Australia. Geographical Research, 44(4), 348-360. doi: http://dx.doi.org/10.1111/j.17455871.2006.00406.X

Australian Bureau of Statistics 2012, Australian Demographic Statistics - Key Figures. Available at: http://www.abs.gov.au/AUSSTATS/

Australian Council for Educational Research 2011, Evaluation of the Sporting Chance Program - For The Department of Education, Employment and Workplace relations, Australian Council for Educational Research, Sydney.

Australian Curriculum, Assessment and Reporting Authority 2012, National Assessment Program - Literacy and Numeracy Summary Report - Preliminary results for achievement in Reading, Writing, Language Conventions and Numeracy, ACARA, Canberra. 
Australian Institute of Health and Wellbeing 2011, Young Australians: their health and wellbeing 2011. Available at http://www.aihw.gov.au/publicationdetail/?id=10737419261\&libID=10737419260 Retrieved 7 April 2015.

Australian Institute of Health and Wellbeing 2012, The health and welfare of Australia's Aboriginal and Torres Strait Islander people: an overview 2011, Australian Institute of Health and Welfare, Canberra.

Australian Institute of Health and Wellbeing. (2012). Healthy lifestyle programs for physical activity and nutrition. Resource sheet no. 9. Canberra: Closing the Gap Clearinghouse. Australian Productivity Commission 2009, Overcoming Indigenous Disadvantage: Key Indicators 2009. Report of the Steering Committee for the Review of Government Service Provision. Productivity Commission, Canberra.

Australian Productivity Commission 2012, Indigenous Expenditure Report. Available at: http://www.pc.gov.au/_data/assets/pdf_file/0007/119356/indigenous-expenditurereport-2012.pdf

Australian Rugby Union 2013, Lloyd McDermott Rugby Development Team.

Australian Sports Commission 2012, The Impact of Indigenous Community Sport ProgramsExecutive Summary, Available at http://www.ausport.gov.au/_data/assets/pdf_file/0003/508134/ Retrieved 7 April 2015.

Bamblett, L. (2011). Straight-line stories: Representations and Indigenous Australian identities in sports discourses Australian Aboriginal Studies(2), 5-20.

Beacroft, L., Lyneham, M. \& Willis, M. 2011, 'Twenty years of monitoring since the Royal Commission into Aboriginal Deaths in Custody: An overview by the Australian Institute of Criminology’, Australian Indigenous Law Review, vol. 15, no. 1, p. 64-84.

Blair, S.N. \& Morris, J.N. 2009, 'Healthy hearts - and the universal benefits of being physically active: physical activity and health', Annual Epidemiology, vol. 19, pp. 253256.

Bradley, S., Draca, M., Green, C. \& Leeves, G. 2007, 'The magnitude of educational disadvantage of indigenous minority groups in Australia', Journal of Population Economics, vol. 20, pp. 547-569.

Cashman, R. 1995, Paradise of Sport: The Rise of Organised Sport in Australia, Oxford University Press, Melbourne.

Coalter, F. 2010, 'The politics of sport-for-development: Limited focus programmes and broad gauge problems?', International Review for the Sociology of Sport, vol. 45, no.3, 3, pp. 295-314. 
Commonwealth of Australia. (2013). Sport - More Than Just A Game: Contribution of sport to Indigenous wellbeing and mentoring. Canberra: The Parliament of the Commonwealth of Australia.

Cottle, D. \& Keys, A. 2010, 'The blindside flick: race and rugby league', Cosmopolitan Civil Societies, vol. 2, no. 2, pp. 1- 11.

Cunningham, J., \& Beneforti, M. (2005). Investigating Indicators for Measuring the Health and Social Impact of Sport and Recreation Programs in Australian Indigenous Communities. International Review for the Sociology of Sport, 40(1), 89-98. doi: http://dx.doi.org/10.1177/1012690205052170

Dalton, B., Wilson, R., Evans, J. R., \& Cochrane, S. (2015). Australian Indigenous youth's participation in sport and associated health outcomes: Empirical analysis and implications. Sport Management Review, 18(1), 57-68. doi: http://dx.doi.org/10.1016/i.smr.2014.04.001

Darnell, S. 2007, 'Playing with race: Right to Play and the production of whiteness in “Development through Sport”, Sport In Society, vol. 10, no.4, pp. 560-579.

Darnell, S. \& Hayhurst, L. 2011, 'Sport for decolonization: Exploring a new praxis of sport for development', Progress in Development Studies, vol. 11, no. 3, pp. 183-196.

Department of Finance and Deregulation 2010, Strategic Review of Indigenous Funding, Report to the Australian Government. Cabinet papers, released under the Freedom of Information Act. Available at: http://www.finance.gov.au/sites/default/files/foi_1027_strategic_review_indigenous_expenditure.pdf Retrieved 7 April 2015.

Donnelly, P., Atkinson, M., Boyle, S. \& Szto, C. 2011 'Sport for development and peace: A public sociology perspective', Third World Quarterly, vol. 32, no. 3, pp. 589-601.

Eagle Edge Solutions 2013, Eagle Edge Solutions - Empowering young people for life. Available at: http://eagleedgesolutions.com/

Farquharson, K., \& Marjoribanks, T. (2006). Representing Australia: Race, the media and cricket Journal of Sociology, 45(1), 25-41

Fredericks, B., Croft, P., \& Lamb, N. 2002, 'Talkin' up sport and gender: Three Australian Aboriginal women speak’, Canadian Woman Studies, vol. 21, pp. 140-142.

Gardiner, G. (1997). Racial abuse and football: The Australian Football League'sracial vilification rule in review. Sporting Traditions, 14(1), 3-25.

Gemmell, J. 2007, 'All white mate? Cricket and race in Oz', Sport in Society, vol. 10, pp. 3348. 
Godwell, D. 2000, 'Playing the Game: Is Sport as good for Race Relations as we'd like to think?’ Australian Aboriginal Studies, nos. 1-2, pp. 12-19.

Hall, S. 1997, 'The Spectacle of the “Other”, in S. Hall (ed.), Representation: Cultural Representations and Signifying Practices, Sage and The Open University, London.

Hallinan, C. \& Judd, B. 2012, 'Duelling paradigms: Australian Aborigines, marn-grook and football histories’, Sport in Society, vol. 7, pp. 975-986.

Hallinan, C. \& Judd, B. 2009, 'Changes in assumptions about Australian Indigenous footballers: From exclusion to enlightenment', Sport in Society, vol. 12, pp. 1220-1235.

Hallinan, C., Bruce, T., \& Coram, S. (1999). Up Front and Beyond the Centre Line: Australian Aborigines in Elite Australian Rules Football. . International Review for the Sociology of Sport, 34, 369-383 doi: http://dx.doi.org/10.1177/101269099034004005

Hallinan, C., Bruce, T. \& M. Burke 2005, 'Fresh Prince of Colonial Dome: Indigenous players in the AFL', Football Studies, vol. 8, pp. 68-78.

Harris, B. 1989, The Proud Champions: Australia's Aboriginal Sporting Heroes, University of New South Wales Press, Sydney.

Hartley, J. (2002). Black, white...and red?: the Redfern All Blacks Rugby League Club in the early 1960s. Labour History (83), 149-171.

Heart Foundation 2013, A submission to the House of Representatives regarding the Inquiry into the contribution of sport to Indigenous wellbeing and mentoring. Available at: http://www.aph.gov.au/Parliamentary_Business/Committees/House_of_Representatives _Committees?url=atsia/sport/subs/sub058.pdf Retrieved 7 April 2015.

Hewitt, J. 1996, Two Blues: 100 years of Mosman Rugby, Team Creative Services, Mosman.

Hibbins, G. (2008). Myth and history in Australian rules football Sporting Traditions, 25(2), 41-53

Hoberman, J. M. 1997, Darwin's Athletes: How Sport has Damaged Black America and Preserved the Myth of Race, Houghton Mifflin, Boston.

Houlihan, B. \& White, A. 2002, The politics of Sports Development: Development of Sport or Development through Sport, Routledge, London.

Howitt,B. \& Deaker, J. 2008, The Converts: Changing Codes, Harper Sports, Auckland.

Hughes, H. 2008 Indigenous Education in the Northern Territory. Policy Monograph 83: Centre for Independent Studies, Sydney. Available at: https://www.cis.org.au/images/stories/policy-monographs/pm-83.pdf Retrieved 7 April 2015. 
Janssen, I. \& LeBlanc, A. 2010, 'Systematic review of the health benefits of physical activity and fitness in school-aged children and youth', International Journal of Behavioural Nutrition and Physical Activity, vol. 7, pp. 40-46.

Janz, K., Letuchy, E., Eichenberger-Gilmore, J., Burns, T., Torner, J., Willing, M. \& Levy, S. 2010, 'Early physical activity provides sustained bone health benefits later in childhood', Medicine and Science in Sports and Exercise, vol. 42, pp. 1072-8.

Kickett-Tucker, C. S. (2008). How Aboriginal Peer Interactions in Upper Primary School Sport Support Aboriginal Identity. Australian Journal of Indigenous Education, The, 37, 138-151.

Kidd, B. 2008, 'A new social movement: Sport for development and peace’, Sport in Society, vol. 11, no. 4, pp. 370-380.

Klugman, M., \& Osmond, G. (2013). Black and proud: the story of an iconic AFL photo. Sydney, NSW: NewSouth.

Levermore, R. 2011, 'The paucity of, and dilemma in, evaluating corporate social responsibility for development through sport', Third World Quarterly, vol. 32, no. 3, pp. 551-569.

Lyons, M. (2001). Third Sector: The contribution of nonprofit and cooperative enterprises in Australia. Sydney: Allen \& Unwin

Malcolm, D. 2007, The SAGE Dictionary of Sports Studies, SAGE Publications, London.

Mallet, A. 2002, The Black Lords of Summer: The Story of the 1868 Aboriginal Tour of England and Beyond, University of Queensland Press, St Lucia.

Maynard, J. 2009, 'Sporting Walkabout - Transnational understandings of Australian aboriginal sporting migration', The International Journal of the History of Sport, vol. 26, pp. 2376-2396.

Maynard, J. 2010, 'Football Barriers - Aboriginal under-representation and disconnection from the "World Game”', in Hallinan, C. \& Hughson, J. (eds), The containment of soccer in Australia: fencing off the world game, Routledge, London.

Maynard, J. (2012). Contested space - the Australian Aboriginal sporting arena. Sport in Society, 15(7), 987-996. doi: http://dx.doi.org/10.1080/17430437.2012.723368

McCausland, R. 2005, The 'New Mainstreaming' of Indigenous Affairs, Jumbunna Research Unit, Briefing Paper no. 3, University of Technology, Sydney. Available at: http://www.jumbunna.uts.edu.au/pdfs/NgiyaMainstreamingBPUpdate.pdf

Nelson, A. (2009). Sport, Physical Activity and Urban Indigenous Young People. Australian Aboriginal Studies(2), 101-111. 
Norman, H. 2012, 'A modern day corroboree - the New South Wales Annual Aboriginal Rugby League Knockout Carnival', Sport in Society: Cultures, Commerce, Media, Politics, vol. 15, no. 7, pp. 997 -1013.

Norman, H. 2009, 'An unwanted Corroboree: the politics of the NSW Aboriginal Rugby League Knockout', Australian Aboriginal Studies, vol. 2009, no. 2, pp. 112-122.

Norris. R. 2001, 'Australian indigenous employment disadvantage: What, why and where to from here?’ Journal of Economic and Social Policy, vol. 15, pp. 13-42.

O’Neill, M. 2005, 'Indigenous sport: the Aboriginal experience in sport', Sport Health, vol. 23, no.2, pp. 11-22.

Oliver, P. 2006, What's the score?: A survey of cultural diversity and racism in sport, Human Rights and Equal Opportunity Commission, Sydney.

Pitsiladis, Y. (2006). East African running: toward a cross-disciplinary perspective. Milton Park, Abingdon, Oxon; New York: Routledge.

Police-Citizens Youth Clubs (PCYC) Indigenous Community Sport \& Recreation Program. Accessed at: http://pcyc.org.au/Indigenous-Programs/Programs-Activities-Events.aspx

Reeve, R. 2012, 'Indigenous poverty in New South Wales major cities: A multidimensional analysis’, Australian Aboriginal Studies, vol. 2012, no.1, pp. 19-34.

Richardson, J. 2012, Indigenous AFL players. Available at: http://pda.sciencealert.com.au/features/20122012-23926.html

Sarra, C. (2005). Strong and Smart: Reinforcing Aboriginal perceptions of being Aboriginal at Cherbourg state school. (PhD), Queensland University of Technology

Skinner, J., Zakus, D. \& Cowell, J. 2008, 'Development through sport: Building social capital in disadvantaged communities', Sport Management Review, vol. 11, no. 3, pp. 253-275.

Stone, J., Perry, W., \& Darley, J. M. (1997). "White Men Can't Jump": Evidence for the Perceptual Confirmation of Racial Stereotypes Following a Basketball Game. Basic and Applied Social Psychology, 19(3), 291-306

Stronach, M. \& Adair, D. 2010, 'Lords of the square ring: Future capital and career transition issues for elite Indigenous Australian athletes', Cosmopolitan Civil Societies: An Interdisciplinary Journal, vol. 2, no. 2, pp. 46-70.

Tatz, C. \& Adair, D. 2009, 'Darkness and a little light: 'Race' and sport in Australia', Australian Aboriginal Studies, vol. 2009, no, 2, pp. 1-14.

Tatz, C. \& Tatz, P. 2000, Black gold: The Aboriginal and Islander Sports Hall of Fame, Aboriginal Studies Press, Canberra.

Tatz, C. 1987, Aborigines in Sport, Australian Society for Sports History, Bedford Park. 
Tatz, C. 1995, Obstacle race, UNSW Press, Sydney.

Tatz, C. 2009, 'Coming to Terms: 'Race', Ethnicity, Identity and Aboriginality in Sport', Australian Aboriginal Studies, vol. 2009, no.2, pp. 15-31.

Tatz,C. 1994, Aborigines: Sport, Violence and Survival. A report on Research Project 18/1989 - 'Aborigines: Relationship between Sport and Delinquency' - to the Criminology Research Council. Criminology Research Council, Sydney.

Tatz, C. (2012). Aborigines, sport and suicide. Sport in Society, 15(7), 922-935. doi: http://dx.doi.org/10.1080/17430437.2012.723352

Tonts, M. 2005, 'Competitive sport and social capital in rural Australia', Journal of Rural Studies, vol. 21, pp. 137-149.

Vos, T., Barker, B., Begg, S., Stanley, L. and Lopez, A. 2009, 'Burden of disease and injury in Aboriginal and Torres Strait Islander peoples', International Journal of Epidemiology, vol. 38, pp. 477-479.

Ware, V.-A., \& Meredith, V. (2013). Supporting healthy communities through sports and recreation programs. Resource sheet no. 26 produced for the Closing the Gap Clearinghouse.

Whimpress, B. 1999, Passport to nowhere: Aborigines in Australian cricket, 1850-1939, Walla Walla Press, Sydney.

Zakus, D. \& Horton, P. 2009, 'Pasifikas in Australian Rugby: Emanant cultural, social and economic issues', Sporting Traditions, vol. 26, pp. 67-86. 